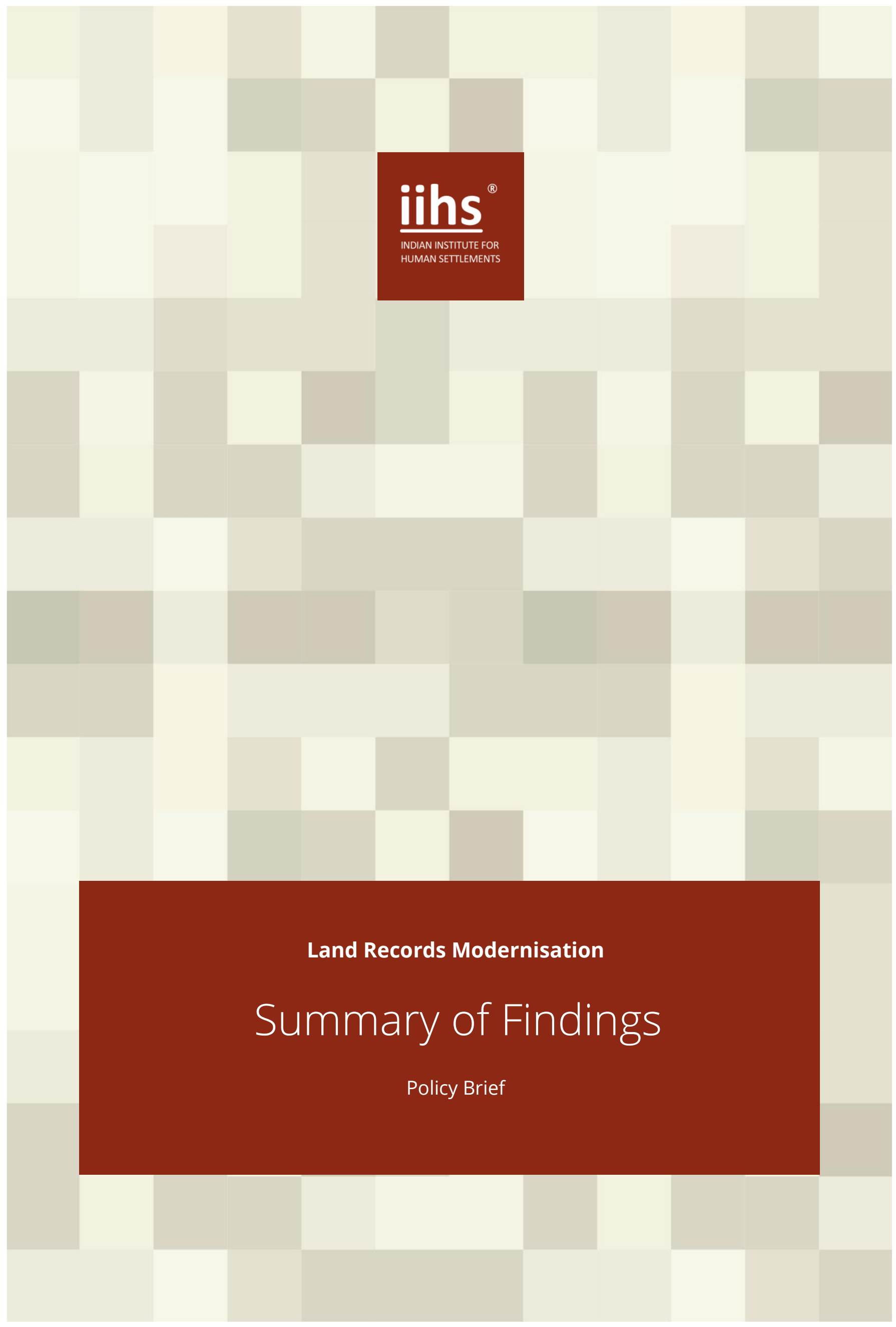




\section{LAND RECORDS MODERNISATION: SUMMARY}

Effective management of land resources is central to a nation's social and economic prosperity. Updated and comprehensive land records play an important role in administering this scarce resource effectively. In India, land records have existed since the pre-colonial period, and were overhauled under British rule. The colonial system, comprising of deeds-based registration and presumptive land records, is still in use.

The benefits of an efficient land records system are manifold:

- Clarity and transparency allow land markets to function efficiently. Financial institutions such as banks benefit if property offered as collateral has no ambiguity in terms of ownership, use and encumbrances. Efficiency in taxation systems is premised on comprehensive records, with accurate details of spatial extent and property classification.

- The judiciary can potentially resolve land disputes faster if updated records are available and recording practices are fair, transparent and allow claims and objections to be heard and resolved.

- The citizen benefits from a clear and transparent land record system available in the public domain.

- The government's poverty alleviation programmes, as well as planning initiatives, can be better delivered if there is clarity on beneficiaries and location particulars (Draft National Land Reforms Policy, 2013)i.

- In eminent domain-related land acquisition, updated and comprehensive land records can facilitate monetisation of various claims and benefits and facilitate smoother payment of compensation, as per the law of the land.

\section{Systemic \& Legal Characteristics of Land Records}

State Subject: As per the Indian Constitution, maintenance of land records, as well as other related aspects such as land revenue, survey and record of rights, are State List subjects. This makes the respective Indian state governments (and not the central government) the primary actors in the record modernisation process. Various central initiatives since the 1980s have attempted to modernise land records in states. Central initiatives, such as a proposed revamped Digital India Land Records Modernisation Programme (DILRMP), should attempt to incentivise state action, while incorporating various state particularities and diversities, stemming from complex and layered histories of land tenureship, settlement and recording of rights.

Revenue Function: Land records have historically served a revenue function and were created for taxation purposes during colonial and pre-colonial times. The primary function of maintaining land records is still held by the Revenue Department in most states. Colonial records were created through extensive surveys and settlement exercises which mapped agricultural land holdings and linked the holdings to owners and tenants. Most states continue to have a Survey and Settlement Department that is closely linked to the Revenue Department. Any land record modernisation effort has to take into account the role of the Revenue Department, while encouraging coordinated action among various other departments. Since land revenue no longer holds much significance, land records have fallen into disuse and need urgent updating. At the same time, with growing urbanisation, land records have once again assumed critical significance.

Deeds-based Presumptive System: India has a deeds-based registration system and presumptive land records. When property transactions/transfers occur using non-testamentary documents, a deed with the transaction details is registered by the Registration Department. Subsequently, the title change caused by the transaction is updated in the land records via a mutation process by the Revenue Department. Changes in ownership occurring through testamentary documents such as wills do not need to be registered and mutation can occur directly and land records are updated. The Revenue Department's land records are presumptive, i.e., they may be challenged in court. Courts therefore play a central role in adjudicating property claims and disputes. 
Basic Types of Land Records: Land records typically comprise:

1. A textual record: A Record of Rights (RoRs), called 'Jamabandi' in many states, comprises of 12 to 13 columns to record details such as ownership, possession, extent of the land holding, etc. Most RoRs have a 'remarks' column, significant in many states, since it allows for a place to note details that other columns cannot capture, including transactions of built-up property in both urban and rural settings. RoRs are land records and not property records.

Any change in the ownership of a land (via sale, gift, inheritance, partition etc.) is reflected in the RoR through a 'mutation' process. In some states, mutation also includes incorporating other changes such as court stays, leases, and mortgages. In practice, however, transactions are often formalised by simply registering the sale deed without a follow-up mutation process, especially in urban areas. Further, the registration process does not validate if the parties engaging in a transaction have the legal right to do so. Caveat Emptor, 'let the buyer beware', is the operative principle. Registrations are not title transfers and are not reflected in land records. Further, many types of institutional transfers, usufruct rights and tenurial arrangements are also not recorded in the RoR. With increasing transactions in land, RoRs provide an incomplete and often non-updated snapshot of legally, financially and socially relevant property rights in an area.

2. A spatial record: The property details in the RoR are supported by a property-level sketch (called 'tatima' in some states) and a larger map showing land holdings in a village and revenue estates that comprise the village. Typically, spatial records are not as updated as the RoR. Furthermore, spatial records often have high error margins. Courts do not accept spatial records as a legal record of spatial extent of a land holding. Often, in case of disputes, the area recorded in the textual RoR is considered. Recent modernisation efforts, driven by the Centre, have aimed at digitising the RoR, the spatial records, and, in particular cases, some states have attempted a realtime updating of the actual on-ground situation with mixed results.

The property-level sketch in the spatial record is drawn and updated at the same time that a new entry is made into the RoR and, in many states, there is an onsite visit by ground-level revenue functionaries who also verify that the transfer is legal and possession has been handed over. The procedures and protocols to update the larger village-level map differ from state to state but typically involve both regular updating by the incorporation of new sketches by ground-level revenue functionaries and also periodic surveys by the Survey and Settlement Department.

\section{Land Records in Urban and Peri-Urban Areas}

Revenue departments in most states typically have poor records for urban and peri-urban areas and village settlement areas. These areas were not covered in the colonial records that focused on agricultural land, which was the main source of tax revenues at the time. Even today, settlement areas of many villages ('Abadi' areas) and cities (which existed in the colonial period) appear as one aggregated revenue estate, with a single survey number in land records, without internal subdivision and ownership details.

A few city surveys were conducted in the Bombay and Mysore regions in the colonial period and some urban records exist in these areas (typically across Maharashtra, Gujarat and parts of northern Karnataka). Post-independence coverage of urban areas has remained incomplete, given high levels of transactions, high rate of urban spatial expansion and the overlapping and expanding jurisdictional boundaries of multiple urban authorities.

Some states such as Himachal Pradesh do not distinguish between urban and rural areas and therefore have some urban records. Some other states such as Karnataka and Gujarat have a system of urban property ownership cards, or property cards. Most cities have municipal tax records, maintained by urban local bodies (ULBs), which enumerate urban properties, but they do not validate ownership and 
cannot be used in court in case of ownership disputes. The primary incentive in municipal efforts to modernise land records is the need to enumerate properties for taxation purposes and not to identify ownership details, since the latter is also fraught with litigation questions.

\section{LRM Initiatives}

The National Land Records Modernisation Programme (NLRMP) was initiated under the central administration of the Department of Land Resources, Ministry of Rural Development, in 2008 (DoLR,

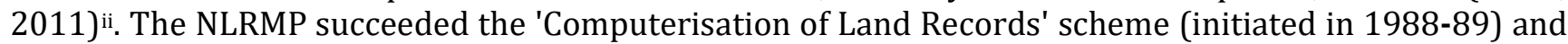
the 'Strengthening of Revenue Administration and Updating of Land Records' scheme (initiated in 1987), and incorporated their objectives, which are computerising of paper records and streamlining of administrative processes. Additionally, the NLRMP advocated a shift from the present legal practice of registering deeds via presumptive land records to a system of guaranteed and conclusive title-based registration. As of December 2015, NLRMP has been formally included under the umbrella of the Digital India initiative, and renamed as the Digital India Land Records Modernisation Programme (DILRMP). Beginning financial year 2016-17, it is also being implemented as a Central Sector Scheme.

DoLR compiles state-wise status of computerisation under DILRMP. As per their latest statistics ${ }^{i i i}$, out of a total of 35 states and UTs, majority have computerised their registration process and their RoRs (30 and 31 , respectively). ${ }^{3}$ However, details are still awaited as to the quality and extent of such efforts. DOLR also notes that several states have stopped manual issue of RoRs (18 states) and placed RoR data on their websites (22 states). However, significantly, as per DOLR, only 11 states have integrated land records with the registration process. Similarly, only five states have integrated Bhu-Naksha with RoR and made it available on their website.

There are also challenges of traction, utilisation and implementation. As of September 2014 ${ }^{\text {iv }}$, state governments had submitted a budget of Rs. 4,298.4 crores (around $\$ 716$ million) v to implement NLRMP, to the central government. The central government had approved Rs. 2,874.7 crores (around \$479 million). Of that amount, by the end of March 2015vi, only approximately Rs. 1,131.1 crores (around $\$ 188.5$ million) had been released by the central government. Out of this amount, it seems, only 38.7 per cent had been utilised by the states.

\section{Challenges of Land Records Reform}

Access, comprehensiveness, facilitating real-time updating and designing replicable protocols to address data mismatches are four main issues in land records reform that require attention. The Department of Land Resources estimates that 80 per cent of 30 million pending disputes across courts in India are land and property related (DoLR, 2011). Ambiguities and non-updated land records contribute to the high level of pendency.

Key characteristics of land records and their management that pose challenges:

1. Data mismatch: In most states, there are mismatches between spatial and textual components of land records, especially as spatial changes are not validated and updated at the time of transaction. There are further mismatches between digitised records and real-time information.

\section{Record of Rights are not comprehensive}

a. All areas are not covered, such as high-value rural and urban settlement areas.

b. All types of properties are not captured, such as built-up properties, mineral rights, air rights, etc.

c. All transfers/ transactions are not captured, such as lease agreements, power of attorney arrangements, mortgages, etc. which could clarify encumbrances, mitigate fraud and facilitate credit access.

d. Different property/ use rights, which have legal, financial and social relevance, are not captured, including community rights, usufruct arrangements, lease markets in urban areas, rights over public amenity areas in cities, rights over forest land, common lands.

e. Institutional land holdings and inter-institutional land transfers are often not recorded. 
f. Land classification categories are mostly rural and there is often no data bridge between land classification in urban areas, statutorily defined by planning and development authorities and those that are legally recorded in revenue records.

\section{Record updating processes are not comprehensive}

a. Individual transactions are not recorded, often because mutation does not usually happen after registration, particularly in urban areas. Several states also face the issue of delays in processing mutation applications.

b. Institutional land holdings, acquisitions, transfers are often not updated in land records.

\section{Lack of institutional integration}

a. Revenue, Registration and Survey Departments are separate in many states, without adequate data bridges between the three departments. States such as Haryana and Himachal Pradesh (HP) have integrated these functions, right up to the district level, which reduces institutional friction.

b. Urban areas: In urban and peri-urban areas, the lack of institutional integration is particularly significant as land data and land administration is spread across many authorities with overlapping jurisdictions. Urban data therefore often exists in institutional data silos.

5. Share system: Land ownership in many states is recorded as 'shares' in the RoR, without physical demarcation. On the ground, legacy practices of possession prevail, which is not reflected in the RoR. The situation can get complicated at the time of transfer/transaction/physical construction/ land acquisition/payment of compensation, etc. The 'share' system is different from common land or lands with community rights, where joint rights prevail.

6. Challenges with technology transitions: Data migration, designing robust modules to capture on-ground differences in recording practices, land transactions and use, creating data bridges between registration and mutation functions and other institutions, etc. presents significant challenges.

7. Capacity challenges: There are also capacity-building challenges to encourage an older generation of ground-level revenue functionaries to become conversant with new technologies. At the same time, newer officials adept with technology need more experience to understand the complexities of revenue functions, without which the technology changes are ineffective.

8. Lack of protocols: Protocols and procedures for dispute resolution to address data mismatches in revenue records are still to be developed at the level of the state. Mismatches are being compounded, where geo-referenced cadastral surveys are being undertaken to update spatial records. Without clear institutional protocols that provide opportunities for claims, objections and dispute resolution, courts are unlikely to give legal credence to the new records and new recording practices being adopted. Clear institutional protocols would also assist officers engaged in the settlement of multiple and discrepant claims on site.

Efforts to modernise land records include digitisation of paper records and making them available and operational through new technology interfaces. These initiatives help in reducing delays, simplifying procedures and improving administrative efficiency, thus improving overall access to records. There is a clear sense that mere technology upgradation, without taking into account specificities of revenue processes in respective states, would not work. A one-size-fits-all approach is unlikely to work in land records modernisation in a country as diverse as India. At the same time, the challenge is to work out particular incentives focused on outcomes (such as reducing litigation) based on the particularities of specific states.

Broadly, there is need to further improve the clarity and comprehensiveness of land records in terms of:
a) spatial coverage,
b) type of properties recorded,
c) type of rights and tenurial arrangements recorded, and
d) type of transactional instruments recorded.

A five-fold typology of classification in terms of ownership, possession, extent, classification and encumbrances could be considered. There is also the need to build systems that will encourage real-time updating of individual, community (village owned) and institutional land and property transactions. 
These details and challenges have specific state-level characteristics which need to be recognised and built upon. Procedures and protocols to address these issues need to be developed at the state-level, with reference to Tehsil and district-level differences, to be successful and sustainable over the long term. This approach has been taken in certain states such as Himachal Pradesh with some degree of success.

i Draft National Land Reforms Policy, 2013, Department of Land Resources, Government of India.

ii DoLR, 2012, Success Stories on National Land Records Modernisation Programme. Accessed at http://dolr.nic.in/dolr/downloads/pdfs/revenue_ministers_document.pdf on 11/04/2014.

iii DoLR, 2016, State-wise Physical Progress as on 16th March 2016. DoLR, Ministry of Rural Development, Government of India. Accessed at http://dolr.nic.in/dolr/downloads/pdfs/DILRMP\%20Physical\%20Progress\%202016-03-16.pdf on $24 / 08 / 2016$.

iv DoLR, 2014: accessed at http://nlrmp.nic.in/faces/rpt/rptApprovedClaim2.xhtml?id=./../master/rpt.xhtml on 05/02/2015 v An exchange rate of USD 1= INR 60 has been used.

vi DoLR, 2015: accessed at http://dolr.nic.in/dolr/downloads/pdfs/NLRMP\%20Financial\%20Progress\%202015-03-31.pdf on $24 / 06 / 2015$. 